\title{
Research on Crowd-funding Financing Risk and Evasion Strategy of Small and Micro Enterprises
}

\author{
Hongxing Liu* \\ Science and Technology College \\ Jiangxi Normal University \\ Nanchang, China \\ jxsdjh@vip.sina.com
}

\author{
Yuanyuan $\mathrm{Yu}$ \\ Business College \\ Jiangxi Normal University \\ Nanchang, China
}

\begin{abstract}
Small and micro enterprises occupy an indispensable position in the development of China's national economy and are an important part of the development of economic entities. Crowd-funding financing is an emerging mode of Internet financing, which has broadened financing channels for small and micro enterprises and promoted financial innovation. This article will mainly through the literature review, to understand the relevant theoretical knowledge of crowdfunding financing at home and abroad, and then through the successful financing case analysis, to explore the various risks of crowd-funding financing of small and micro enterprises, such as credit risk, legal risk, property rights risk, etc. At the same time, the corresponding opinions and suggestions are put forward for the above problems.
\end{abstract}

Keywords-Small and micro enterprises; Crowd-funding financing; Risk; Countermeasure

\section{INTRODUCTION}

With the development of China's market economy and the progress of society, the role of small and micro enterprises has become more and more important. Not only does it solve a lot of employment problems for the society, but the contribution to GDP and taxation cannot be ignored. The "new normal" was first proposed by General Secretary Xi Jinping during his inspection in Henan. Its characteristics are mainly reflected in the new normal of economic development, from high-speed growth to medium-high-speed growth, economic structure optimization and upgrading, from factor-driven, investmentdriven to innovation-driven. Political and social construction also presents a new normal. Under the influence of this new trend of economic development, the innovative advantages of small and micro enterprises can maintain the current economic development speed in China at a medium to high level and win time for economic transformation.

However, small and micro enterprises have been facing many problems in development since their appearance. With the changes in the economic situation, more and more small and micro enterprises have been in trouble, and the global problem of financing is once again raised. As a result, a new financing model emerged as the times came - crowd-funding.

\section{RESEARCH PURPOSE AND RESEARCH SIGNIFICANCE}

The purpose and research significance of this paper is to propose targeted, constructive and operational suggestions, in order to provide theoretical support for the practical operation of crowd-funding financing risk prevention in China, thereby reducing the creative financing of creative individuals and start-up small and medium-sized enterprises in China, promoting the effective flow and rational allocation of capital, protecting the legitimate rights and interests of investors, and ensuring the healthy development of crowd-funding financing.

\section{RESEARCH METHODS}

This article takes the Yuedi mother project as a case to explore various risks in the crowd-funding financing of small and micro enterprises. The research methods of the thesis mainly include literature analysis method and case analysis method, combining theoretical research with case study to analyze domestic small Micro-enterprise crowd-funding.

\section{A. Document Analysis}

By understanding relevant theories at home and abroad and domestic scholars' research on crowd-funding financing of small and micro enterprises, combing and summarizing the theoretical results of scholars at home and abroad, they have a basic grasp of small and micro enterprise crowd-funding financing, and have a certain theoretical basis. Subsequent case studies provide better theoretical support.

\section{B. Case Analysis}

A real crowd-funding success story was selected as the research object, and its financing model, process and effect were analyzed in detail. The advantages of crowd-funding financing were demonstrated, and more small and micro enterprises were attracted to obtain funds for the project through crowd-funding financing.

\section{DOMESTIC AND INTERNATIONAL REVIEW}

\section{A. Small and Micro Enterprise Financing Status}

Zhang Rongbin [1] analyzed the reasons for the difficulty of financing small and micro enterprises, and believed that the scale was small, the assets were small, and the risks were high. However, with the help of the Internet to reduce its cost, the use of Internet big data, the wide platform features help small and micro enterprises to get rid of financing difficulties.

Liu Xinteng [2] first cut through the importance of small and micro enterprises, indicating that small and micro enterprises play an important role in increasing China's 
employment, maintaining social stability and technological innovation, and are an important part of China's economy. Therefore, it is difficult to solve the financing difficulties in small and micro enterprises. The problem is particularly urgent, and the financing dilemma is solved by combining the characteristics of small and micro enterprises and the real market environment.

Ren Peicui [3] believes that the key to the financing difficulties of small and micro enterprises is that they have insufficient self-owned funds. A large number of Chengdu relies on banks, and the financing in the stock market is also restricted. It is also mainly analyzed from the internal and external factors of the enterprise the phenomenon of financing dilemma for small and micro enterprises. Make targeted recommendations through analysis of specific issues.

Hauswald, Agarwal [4] believes that the small and micro enterprises have difficulty in lending, because the credit rating system of small and micro enterprises is not perfect, the entry threshold is higher, and the small and micro enterprises that use the Internet as the financing model can relatively reduce the conditions of credit rating, and easy to finance.

Udell, Bergrt [5] analyzed the financing of small and micro enterprises, and believed that the society lacks understanding of the economic status and future development of small and micro enterprises. Only the surface of small and micro enterprises can be observed, that is, the scale is small, the management mechanism is backward, and information technology Non-standard, in this case, the financing difficulty of small and micro enterprises is intensified. Often, these small and micro enterprises can only choose internal financing when there is a shortage of funds.

\section{B. Crowd-funding Definition}

Xiao Benhua [6] believes that crowd-funding means that financiers use the Internet platform to finance their projects or companies for a wide range of public investors. Investors only need to invest a small amount of money to get the corresponding physical or equity returns from the financiers.

Yuan Kang [7] pointed out that crowd-funding financing is mainly based on the Internet, and the collective investment of the public investors to complete the financing. The more basic operating model is that the fund demander releases the capital demand on the platform, and the website will announce how the funds will be used. If the public is interested in the project, they can voluntarily invest and obtain the corresponding substances according to the prior agreement.

Molick [8] has researched crowd-funding as an innovative financing model that uses the Internet as a medium. Many investors invest money to help projects start for the purpose of interest, culture, philanthropy or value return.

\section{Crowd-funding Characteristics}

Huang Jianqing [9] pointed out that the difference between crowd-funding financing and traditional financing is that it can reduce the financing risk to a certain extent, thus setting up a private investment and financing platform and playing a "nonintermediary" financing role. It can be seen that crowd- funding financing has certain practical application value in realistic operation and economic development.

Eleanor Kirby \& Shane Worner [10] divides crowdfunding into four categories, which are "donation crowdfunding" formed by charitable donations. "Rewarding crowdfunding" achieves the purpose of goods or services. In order to obtain personal or corporate claims, the "debt crowd-funding" formed by the recovery of principal and interest in the future. "Equity Crowd-funding" formed by means of obtaining corporate equity. Among them, equity crowd-funding is the fastest-growing crowd-funding method in recent years.

$\mathrm{Wu}$ Qi [11] said in the international academic conference that the funding problem has always been the main bottleneck restricting the healthy development of small and micro enterprises. Crowd-funding financing makes full use of the fast, open and flexible nature of the Internet, and can quickly and efficiently solve the financing problems of small and micro enterprises and promote economic growth. The crowdfunding financing is divided into four categories: "equity crowd-funding", "debt crowd-funding", "reward crowdfunding" and "donation crowd-funding".

\section{The Risk of Crowd-funding}

Dong Hanguo [12] analyzes the custody of equity crowdfunding equity crowdfunding. Through the axis of investor maturity and project risk, the government is at the regulatory level to balance the choices, combined with the experience of the US JOBS Act. Proposing for deregulation can promote corporate finance and development.

Andyley and Scott Weaven [13] studied the risk of crowdfunding model from the perspective of principal agent and analyzed the risks faced by investors before and after investment.

\section{CASE STUdy - TAKING THE YUEdI MOM PROJECT AS AN EXAMPLE}

Nie Qiaole, who specializes in prenatal education, has established the "Nie Qiaole-Interactive Experience-style Preadults Method" and the "Interactive Experience-based Early Childhood Education Law" through seven years of professional experience, and proposed a family parent with mother education as the core and family education as the principle. The educational concept, in 2007, opened a leading professional prenatal education institution in China, a Yuedi mother. Funding is needed for business development and the impact of prenatal education in China needs to be expanded. Applying for a loan from the bank, due to the cumbersome banking procedures, strict review, and no approval for one month, the company abandoned bank loans and chose Angel Street for equity crowdfunding.

After financing through equity crowdfunding, Yuedi Mama Company obtained 2 million financing funds to provide sufficient capital for its business development; and obtained a multi-million dollar venture capital of Hongtai Fund, which made the company's valuation It has increased nearly 10 times; Angel Street crowdfunding platform helps it integrate planning company management modules, introduces senior 
investors' management experience, media platform promotion opportunities, and successfully connects partners in dual downstream industries, making business operations more convenient; What is important is that the online and offline publicity activities not only promote the company, but also spread the concept of prenatal education and family education, so that more people can participate in the prenatal education, pay more attention to the importance of family education, and the society it brings. The significance is far greater than the commercial value.

The successful experience of the Yuedi mother project: The early stage of the project is limited in scale. It has certain difficulty in entering the capital market. It is financed through the publicity of crowdfunding, and it has also gained the recognition of the mass market while entering the capital, and accepted the market. The opinions and feedbacks have improved the links of all aspects of $\mathrm{O} 2 \mathrm{O}$ and laid a solid foundation for the progressive capital market, so they can receive funding from Hongtai Fund.

\section{THE RISK OF SMALL AND MICRO ENTERPRISE CROWD-} FUNDING FINANCING

\section{A. Credit Risk}

First, the public financing platform did not conduct a comprehensive audit of the qualifications of the fund and the risk of failing to meet its commitments after the fund was successfully raised. In addition, for ordinary investors, because they are not familiar with project information, lack of professional investment risk estimates, increased investment risks. Moreover, anyone can now issue financing projects on the Crowd-funding platform, which may cause credit risk and risk manipulation problems.

On the crowd-funding platform, tracking the use of funds is difficult to track, and because of the lack of clear institutional requirements, financing companies are not fully aware of the use of funds and the company's profitability. It is difficult for investors to track investment trends and protect themselves. Return on investment. Once the target company flies successfully or declares bankruptcy, the investor's rights cannot be guaranteed, let alone the income from investment, and investors will face huge losses.

\section{B. Legal Risk}

In order to promote public financing and integrate more investors into new financing models, most of China's public financing platforms adopt a "leadership and follow-up" model. Professional investors act as lead investors, and ordinary investors invest in projects selected by the lead investors. However, in practice, due to the lack of some equity financing platforms lacking the supervision of professional leading investors and the regulation of investment methods, coupled with the information asymmetry faced by investors, the role of "leaders" is difficult to be clearly defined. At present, due to the lack of supervision of equity financing, the leader may collude with the financiers and maliciously recommend stocks, which makes some investors blindly follow the trend. When the financiers obtain a large amount of financing, they will use the excuses of investment failure to make the investors suffer heavy losses.

\section{Property Risk}

Compared with traditional financing methods, Crowdfunding financing has certain requirements for the openness of project content. The network is virtual and open. Small and micro enterprises must publish the project in the process of Crowd-funding financing. The Crowd-funding platform can approve the project according to the value and feasibility of the project plan. In the process of financing, investors also need to evaluate according to the project content. Whether it is supported, because the funders of Crowd-funding financing are people who are concerned about the whole network, small and micro enterprise projects may be stolen and copied by others in advance, and the core of the Crowd-funding financing project itself is creativity. Once it is imitated, the project's The value will be reduced, and it may be difficult to meet the previous expectations. The intellectual property rights or patent rights of small and micro enterprises will be impaired.

\section{STRATEGIC CHOICES FOR SMALL AND MICRO ENTERPRISES TO AVOID CROWDFUNDING FINANCING RISKS}

\section{A. Strengthen Credit Monitoring}

Creating a good atmosphere of integrity is important for the development of Crowd-funding. Because the operations of the Crowd-funding industry are carried out through the network platform, there will often be some online fraud, cybercrime and so on. Because the supervision system and integrity supervision are not perfect, some Crowd-funding issuers will move the funds to other places, resulting in investors not getting a reasonable return, so that the public loses trust in the Crowd-funding website and Crowd-funding industry. Therefore, it is necessary to set up a special financing platform review team to conduct a rigorous evaluation of the project sponsor's qualifications, so as to improve the reliability of financing, and at the same time, according to the safety factor of each Crowd-funding financing and possible risks, formulate standardized financing steps, to publish accurate financing warning information, and strengthen the monitoring of all aspects of Crowd-funding financing to ensure the investor's financial security and the interests of both the initiator and the investor.

\section{B. Strengthening the Construction of Laws and Regulations}

At present, Chinese authorities should formulate laws and regulations on the field of crowd-funding as soon as possible, and should be refined into each branch, which should include the definition of crowd-funding financing, the financing system, and the difference from illegal fund-raising, so that crowd-funding financing It has a clear legal basis and can be well developed in China. At present, the field of crowdfunding financing in China is still in the growth stage. There is still no clear and clear explanation of the relevant definitions and scopes. This makes people unable to have a correct understanding of crowd-funding financing and often associates with "illegal fundraising". At present, some crowd-funding 
websites worry that they will violate the regulations and impose certain requirements on financing conditions in accordance with relevant regulations. These requirements will dispel people's enthusiasm and affect the operation and development of the crowd-funding industry.

\section{Strengthen Property Rights Protection}

Property rights are the key to Crowd-funding financing for small and micro enterprises, and also the core of the project. It is directly related to the promotion of small and micro enterprises. The protection of property rights is very important. The property rights of Crowd-funding enterprises can be protected from the following aspects: first, small Microenterprises should apply for property rights before the project application to ensure ownership. If there is a case of being stolen, legal action can be taken to defend rights. Second, in the process of project approval and pre-publication, small and micro enterprises can selectively announced to reduce the possibility of project core fraud and copying. Third, in the project financing process, you can choose to announce the project direction to investors, and the key parts such as the creative core or technology core can choose to keep confidential, indicating the reason. Get the understanding of investors.

\section{VIII.SUMMARY}

As a new type of Internet financing model, the crowdfunding financing model uses the network platform to publicize and display the project, and gathers the small funds of the public investors to directly connect with the small and micro enterprises to solve the financing of small and micro enterprises demanding. The problem of financing difficulties for small and micro enterprises in China has been widely concerned. It is difficult for small and micro enterprises to obtain the funds needed for enterprise development through traditional financing methods. However, Internet finance has opened the door for small and micro enterprises to achieve financing. Among them, the crowd-funding financing method is the best choice for small and micro enterprises financing because of its low cost, short financing time, high efficiency and additional benefits. Completely solve the problem of financing difficulties for small and micro enterprises.

This paper cites the case of small and micro enterprises successfully financing through the crowd-funding financing model, and the additional effects brought by it are also difficult to achieve in the traditional financing model. In the fourth part, we sort out the domestic and foreign literatures of crowd-funding financing, combine the theoretical basis with the successful financing cases, and explore the existing financing risks such as credit risk, legal risk and property rights risk of crowd-funding financing of small and micro enterprises. Risks provide corresponding opinions and suggestions to further promote the sustainable and sound development of crowd-funding financing, and effectively solve the difficult financing problems encountered by small and micro enterprises in China.

\section{ACKNOWLEDGMENT}

This paper is one of the research results of The Research on Innovation of Financing Models of Small and Micro Enterprises in China under Internet Finance in The Research Project of the Science and Technology of Jiangxi Provincial Department of Education.

\section{REFERENCES}

[1] R.B. Zhang, "Innovation of small and micro enterprise financing in the Internet financial environment," Economic and Trade Practice, vol. 03, pp. 84, 2016.

[2] X.T. Liu, "Reflections on the financing of small and micro enterprises in the new era," Modernization of shopping malls, vol. 03, pp.187, 2015.

[3] P.C. Ren, "The financing dilemma and countermeasures of small and micro enterprises," Enterprise Reform and Management, vol. 7, pp. 115194, 2016.

[4] S. Agarwals and R. Hauswald, "Distance and private information in lending," Access\&Download statistics," vol. 7, pp. 2757-2788, 2010.

[5] A.N. Berger and J.F. Udell, "The Econmics of Small Business Finance:The Roles of Private Equity and Debt Markets in the Financial Growth Cycle," Journal of Banking\&Finance, vol. 6, pp. 613-673, 1998.

[6] B.H. Xiao, "The development and enlightenment of the US public smallfunding model," Securities Market Herald, vol. 05, pp. 50-54+61, 2013.

[7] K. Yuan, "The construction and supervision of public small-scale fund raising in the Internet age_- Taking the US JOBS bill as a reference," Securities Market Herald, vol. 06, pp. 4-13+20, 2013.

[8] E.R. Mollick, "Swept away by the crowd crowd-funding, venture capital, and the selection of entrepreneurs," Venture Capital, and the Selection of Entrepreneurs, vol. 8, pp. 496-531, 2013.

[9] J.Q. Huang and Q.L. Xin, “"Crowd-funding”-The concept, characteristics and enlightenment of the new network financing model," International Finance, vol. 09, pp. 64-69, 2013.

[10] K. Eleanor and W. Shane, "Crowd-funding:An Infant Industry Growing Fast," Staff Working Paper of the IOSCO Departmnet, 2014(7), pp. 1323-1326.

[11] Q. Wu, "Research on the impact of crowd-funding on small and micro enterprises," AEIC Academic Exchange Information Centre(China). Proceedings of 2018 4th International Conference on Humanities and Social Science Research(ICHSSR 2018)(Advances in Social Science, Education and Humanities Research VOL.213) [C].AEIC Academic Exchange Information Centre (China): International Conference on Humanities and Social Science Research, 2018: 4.

[12] G.D. Han and Z.Y. Mai, "Supervision logic and international experience of equity crowd-funding financing," Ningxia Social Sciences, vol. 1, pp. 97-100, 2016.

[13] L. Andy and W. Scott, "Exploring agency dynamics of crowd-funding in start-up capital financing," Academy of Entrepreneurship Journa1, vol. 1, pp. 3-40, 2011. 